\title{
The Transition from Hospital to Home: Older People's Experiences
}

\author{
Sigrun Hvalvik1,2, Bjørg Dale ${ }^{2,3}$ \\ ${ }^{1}$ Faculty of Health and Social Studies, Telemark University College, Porsgrunn, Norway \\ ${ }^{2}$ Centre for Caring Research-Southern Norway, Telemark University College, Porsgrunn, Norway, and University \\ of Agder, Grimstad, Norway \\ ${ }^{3}$ Faculty of Health and Sport Sciences, University of Agder, Grimstad, Norway \\ Email: Sigrun.Hvalvik@hit.no, Bjorg.Dale@uia.no
}

Received 31 May 2015; accepted 12 July 2015; published 15 July 2015

Copyright (C) 2015 by authors and Scientific Research Publishing Inc.

This work is licensed under the Creative Commons Attribution International License (CC BY).

http://creativecommons.org/licenses/by/4.0/

(c) (i) Open Access

\begin{abstract}
The amount of older patients who are discharged from hospitals while continuing to need care is increasing in Norway. The transition between different care services has the potential for high rates of medication errors, incomplete or inaccurate information transfer, and lack of appropriate follow-up care. Thus, insight into the transition process is vital to understanding the complexity and vulnerability the patients are exposed to in this process. The aim of this phenomenological hermeneutic study was to describe and illuminate the lived experiences of older home residents during the transitions from hospital to home. Data were collected through narrative interviews, and an interpretation analysis based on a method developed by Lindseth and Norberg was conducted. Two themes and four subthemes, closely related to each other emerged from the structural analysis of the text: The theme "Relating to different systems of care" with the two subthemes "feeling disregarded" and "being humble"; and the theme "Adapting to life conditions" with the two subthemes "feeling vulnerable" and "coping with alterations". The older people miss being seen as human beings as well as patients during the transition process. Despite the lack of information and participation in the transition process, they were grateful and humble to the systems of care they were a part of. This, however, also encompassed rejections of own needs. It is urgent that health care professionals focus on the older person's individual needs and preferences. This means that care must be considered from the perspectives of the older person's biographical as well as medical history, and the complexity of the situation.
\end{abstract}

\section{Keywords}

Adaptation, Care Systems, Neglect, Phenomenological Hermeneutic Approach, Vulnerability 


\section{Introduction}

The amount of older patients who are discharged from hospitals while continuing to need care is increasing in Norway [1]. This is, among other things, a result of the Coordination Reform [2] which took effect in January 2012. The reform emphasizes that older patients should be discharged to their home municipalities as quickly as possible after treatment in the specialist health services [2]. Older patients are often burdened with complex medical and social needs and are at great risk of rehospitalisation [3]. Furthermore, the transition between different care services has the potential for high rates of medication errors, incomplete or inaccurate information transfer, and lack of appropriate follow-up care [4]. Hence, these kinds of transitions are exchange points that expose chronically ill people to lapses in quality and safety [5].

From a transition perspective, one major goal in nursing is to facilitate healthy transition processes and prepare and help the patient to meet challenges [6]. Thus, knowledge of various aspects of the transition process is vital. To recognise and meet the patient's needs in the best and most professional way, it is important to gain insight into their own experiences with the transition. Such insight is also essential to realize ambitions described by the Ministry of Health and Care Services in several reports [2] [7]. The reports stress the significance of supporting the patient to participate actively in health care decision making. Likewise, the reports maintain the importance of respect and empathy as well as the patient's right to determine her or his own ends. Similar ideals are embedded in the framework for the humanisation of care developed by Galvin and Todres [8]. Advocating humanisation of care means supporting the person's uniqueness and dignity in care and greater patient choice.

Recent research regarding the topic of this study has mainly focused on hospital discharge of older patients, and readmission and return to the hospital [3] [9]-[13]. These studies have pointed out that information and communication between the health care providers and patients and their family caregivers is vital. In a study of older home resident's experiences with the transition from self-supported to supported living, Hvalvik and Reierson [14] state that insight into the transition process is vital to understanding the complexity and vulnerability the patients are exposed to in this process. Foss and Hofoss [15] concluded in a study of older hospital patients' discharge experiences that the actual practice of involving the patients in the discharge process was not well developed. These findings were supported by Foss et al. [16], who also indicate major shortcomings in participation, information and education in the discharge process. In a study of factors predicting successful post-discharge outcome, Bragstad et al. [17] found that having someone at home upon return from the hospital and during formal home care services was significantly associated with patient-reported success in managing own health.

In short, these studies are important for conceptualising discharge challenges and demonstrate the necessity of additional research that focuses on the transition from hospital to home. The present study aims to describe and illuminate the lived experiences of older home residents with continuing care needs during the transition from hospital to home.

\section{Methods}

The study has a phenomenological hermeneutic design. Accordingly, the epistemological approach is embedded in phenomenological and hermeneutic philosophy, explicated by Dahlberg, Dahlberg, \& Nystrøm [18] as a reflective life world approach. In this approach the focus on how the world with its everyday phenomena is lived, experienced, acted and described by humans, is fundamental [18]. Thus, our goal is to grasp the meaning of the phenomena and describe and illuminate them in ways that expand our understanding of humans.

\subsection{Participants}

A purposive sampling method based on the following inclusion criteria was used to recruit participants:

- patients were 67 years or more,

- were cognitively able to give consent,

- had been discharged from hospital the last 2 - 8 weeks, and received home care after returning home

Home care offices in two municipalities in southern Norway were informed about the study and asked if they were willing to participate and cooperate in participant recruitment. Ten participants were recruited by the home care offices and further contacted by the researchers. Due to worsening illness, three participants withdrew prior to the interviews. The seven remaining participants consisted of two men and five women. (Further characteris- 
tics of the participants are described in section 3.2).

\subsection{Data Collection}

Individual narrative interviews were conducted by both authors. The interviews took place in the participants' homes during spring/autumn 2014 and lasted about one hour. They were audio taped and transcribed verbatim by the researchers. The participants were encouraged to communicate as freely as possible about how they experienced to be discharged from hospital and to return home and start or continue with homecare. They were asked to talk about negative as well as positive experiences and to expand or explain their understandings. As for example: "You say that you were confused when you were discharged, can you tell me a bit more about this?" Both researchers were also well seasoned nurses and had a basic understanding of the phenomenon under investigation. They had discussed and reflected upon the subject before and during the interview process, trying to uncover and broaden their preconceptions, and to maintain an open and flexible attitude in the interview situation [19].

\subsection{Data Analysis}

A phenomenological-hermeneutic approach was used to understand and interpret the meaning of the lived experiences as narrated by the older persons in this study. The method was developed by Lindseth and Norberg [18] and grounded in the philosophical assumptions of Paul Ricoeur [20]. The method comprises the following three stages: 1) naïve reading, which is a concept used specially in this method, is the phase where the interpreter seeks to grasp an initial understanding of the text as a whole; 2) structural analysis, which includes confirmation of the initial understanding of the naïve reading through several examinations of the parts in the text formulated as themes and subthemes; and 3) comprehensive understanding, which is an in-depth interpretation. On this stage the text is read once again as a whole and further reflected on in light of the interpreter's pre-understanding, the results emerging from the naïve reading and the structural analysis, and relevant literature to achieve a deeper understanding of the text [18].

Following these stages the researchers read the text several times to understand it as a whole and then formulated a naïve understanding of the interview texts. Stage 2 was executed as a thematic structural analysis. The text was further divided into meaning units and reflected on in relation to the naïve understanding. The meaning units were condensed to grasp what the text talked about. The meaning units were related and rephrased and subthemes and themes were identified and formulated. During the analyzing process, the two researchers worked both separately and together. They formed the final subthemes and themes together and validated them by comparing them with the naïve understanding. Finally a comprehensive understanding was formulated based on reflections on the text, the naïve understanding, and the themes in association with the aim and the context of the study. In this interpretation process the preunderstanding cannot be set aside and therefore constitute an essential condition for the dialogue with the text [18] [19].

\subsection{Ethical Considerations}

The study was implemented in accordance with the Declaration of Helsinki [21]. Study approval was obtained through the Regional Committees for Medical Research Ethics, South East Norway (2013/2046 sør-øst B). Formal access to the field was made through the municipal authorities. Leaders, health care professionals, and participants were informed verbally and in written form about the study. The participants were informed at least twice, and their legal rights were repeated prior to each interview and before they signed the consent form [22].

\section{Results}

\subsection{Naïve Reading (the Initial Understanding of the Text)}

Being an older patient in transition from hospital to home means to experience lack of involvement in the transition process and to miss communication with significant health professionals at the hospital and in the home care. As a result the older patient feel invisible and also uncertain of own health condition. However, the older patient accept the situation without complaints. During the transition process the older patient experiences that life conditions are changed. Having to cope with these changes makes the older person vulnerable and chal- 
lenges her or him in different ways.

\subsection{Structural Analysis}

Two themes and four subthemes, closely related, emerged from the structural analysis of the text. The themes reflected the meaning of the older patients lived experiences during the transition process from hospital to home as narrated by them. The two men in the sample were more than 80 years old and lived with their spouses. Four of the women were in their eighties. One of them lived together with her spouse; three of them were widows or lived alone. One woman was in her seventies and lived alone. They had been hospitalised for acute disease or injury, or exacerbation of chronic disease. Some of them had received home care before hospitalisation, while others started home care after returning home. Although distinct variations, the following themes and subthemes were generally valid for the participants: "Relating to different systems of care", with the two subthemes "feeling disregarded" and "being humble"; and "Adapting to life conditions" with the two subthemes "being vulnerable" and "coping with alterations". An overview of the themes and subthemes is shown in Table 1.

\subsubsection{Relating to Different Systems of Care}

This theme reflects the older person's endeavours to relate to the various caring systems during the transition from hospital to home. These endeavours were characterized by feeling disregarded and also of being humble in relationships with health care professionals.

Feeling disregarded means experiencing uncertainty, worries and unmet needs. Older people are challenged by consequences related to their medical condition without feeling sufficiently prepared to deal with them. During the transition they endeavour to adapt to various health care settings and professionals in order to cope with the situation. Being in the hospital means that they are in a context where they expect to be treated and receive help for their illnesses and medical problems. Frail, but still returning to continue life in their own homes, it is crucial that they are familiar with their medical condition and prepared to deal with its consequences in a best possible way. Although the participants appreciate and recognise the medical treatment they are given at the hospital, they feel they have questions and needs that remain unmet. They also have the feeling of being left alone most of the time. This makes them disappointed and frustrated, and they are worried about how to deal with their health problems after discharge. An older person who had been exposed to a severe leg injury stated:

I thought it was very strange that I was discharged, as I hadn’t had the opportunity to try to walk on my foot. So far I had used a wheel chair, and then suddenly I was sent home! I was so frustrated! I had expected to exercise as well as to be informed about how to further regain my function. And the only thing I got was a brochure with exercises (...)

Another mentioned that: “They just give me oxygen; that's it. (...) I'm not satisfied with that. They should have explained things better, and examined me better.” The narratives demonstrate that older people also leave the hospital without a final talk with the doctor or other health care professionals at the hospital. This is described as a loss as they expect the discharge to give them an opportunity to ask questions and receive information about their health status and further precautions.

After having returned home, the older person experience that health care professionals in the municipality seldom are interested in the diagnosis or in the treatment they have received, nor in their hospital stay as such. This represents concerns about whether they get the right follow-up and necessary help after the hospital stay. According to one older person:

Table 1. An overview of the themes and subthemes.

\begin{tabular}{|cc|}
\hline \multicolumn{2}{|c|}{ Themes } \\
\hline Relating to different systems of care & Adapting to life conditions \\
\hline Subthemes & Subthemes \\
\hline Feeling disregarded & Being vulnerable \\
Being humble & Coping with alterations \\
\hline
\end{tabular}


They don’t care. They don't talk much, and certainly not about my stay at the hospital! They ask, "Do you want me to cook for you?” I almost have to laugh. You know, they have too little education and I don't trust them to manage my B-pap.

Experiencing this lack of interest and also neglects of their medical history makes the older patients upset and worried. One of them told:

They don't know what the patient has gone through. "Oh, Jesus”, the nurse said to me. "Have you got a pacemaker?” All those who have anything to do with you should know your medical history!

The narratives indicate that the health care professionals, both at the hospital and in the home care, perform their tasks without having the older person's specific needs in focus. Furthermore, they show different foci and ambitions between the two systems of care. At the hospital the care is oriented towards illness and medical treatment, and in the home care it is oriented towards the patients' daily functioning. This threatens the older person's sense of coherence in the transition process. Experiencing this inconsistence is stressful and generates uncertainty and concerns of how to deal with the situation.

Being humble reflects the participants' attitudes towards the systems that they are part of in the transition process. Being humble means to accept unpredictability and not being involved. These attitudes are included in the stories related to the discharge process, which usually comes as a surprise to the older people, indicating their lack of involvement in the transfer process prior to returning home. One participant described: "After the doctor's visit the nurse said to me, 'You are lucky, Mrs. Smith, you may leave the hospital today!'” Although not feeling ready to leave, they seem to accept to be discharged without further discussion. Another participant expressed: "I wish I could have stayed one more week, but of course I cannot. They say I should go home, so I should, huh?"

Being humble means accepting care conducted or arranged without the older person's consent. Reflecting on her return home, one participant with some special needs narrated:

The first days after I arrived to my home, they said that I had to have a commode in the living room. This was very hard for me. I had to promise not to go to the toilet, and I tried to be obedient, as I know they feel responsible. Nevertheless, I really struggled, I got wet, and my bed and my clothes got wet. So I thought, “now I'm going to break my promise. I just can’t bear this situation”. Why couldn't I have got more time at the hospital?

The discharge summary, i.e. the document that follows the patient from hospital back home, is merely perceived as a formality. The older people themselves do not understand the summary's contents, and nor do health care professionals offer any explanation to what it says. This seems to be quite natural and acceptable for the older patients. One of them said: "I got some papers with me. However, there are so many weird words. I understand nothing. But I won’t nag at them”.

Being humble also means accepting a large number of nurses to relate to and interact with in the initial period after returning home. The narratives reflect that the participants consider this a disadvantage, however, they do not want to complain. The disadvantages are associated with the fact that the older people have to relate to nurses with various competencies, and with more or less knowledge of them as individuals, of their medical condition and history. This is perceived as exhausting and sometimes worrisome. The participants also notice that a large number of nurses increases the risk of communication failures and insufficiencies between the nurses. One older person said: “There's far too many of them! They forget to pass on important messages to each other. It really irritates me!” Furthermore, the participants adapt to irregular visits and busy nurses with limited time to attend to their preferences. Being humble thus means that the older persons have to suppress their own desires. As one older person mentioned,

I would have loved to talk with them about my situation and about what happened to me at the hospital. However, when the first thing you hear is, “Oh, I’m so busy today!”, you don't even suggest it!

Being humble means that the older people do not want to impose requirements or critics. According to one participant, “They are doing their best. There’s nothing wrong with them; it's the system”.

\subsubsection{Adapting to Life Conditions}

This theme reflects challenges the older patients have to cope with in transition from hospital to home. Adapting 
to life conditions involves being vulnerable and having to cope with alterations.

Being vulnerable reveals the experiences of being ill, old and frail, and dependent on professional support. During the transition, older people find themselves in contexts that are more or less unfamiliar, and in need of help to various degrees. Their narratives describe desires to be understood, cared for and seen as both individuals and patients by the health care professionals, and thus reveal their vulnerability in the process. Being vulnerable includes to be sensitive to health care professionals, their attitudes and actions. One of the participants told the following about the first time she walked to the toilet herself at the hospital:

You know, they wanted me to stand up and go and to stop using the commode or wheelchair. I felt quite exhausted when I came to the bathroom. "And what do you use to do when finishing at the toilet", the nurse said. "I use to wipe myself”, I said, quite unhappily. "Well, do it then”, the nurse continued, "I'll wait for you outside!” Is that worthy for an old human being?

Being vulnerable means to be bewildered of how to deal with health related problems and symptoms as this underscores the older people's dependence and helplessness. The narratives indicate that they use various strategies to compensate for their lack of knowledge and mastery by assigning responsibility to next of kin, trivialising the situation, or by highlighting their own strength or faith in medicine. Three statements emphasize this:

Of course, it would be interesting to get an explanation of what happened with my heart. Anyway, I think

it's strong and good. I only hope I won't have to experience that anxiety when I get home.

In fact, I got no information about the operation or advice on how to behave afterwards. However, I think

it was a simple operation, and the doctors are very clever, so I'm thankful for the job they did.

They help me take a shower, so that's very all right! I try to manage the training myself. I'm happy to receive the help I get. I think about all those who have it worse than me. Poor people!

Hence, being vulnerable includes having to strive to preserve self-respect and dignity in relation to the challenging circumstances that are incorporated in the transition from hospital to home.

Coping with alterations means having to cope with changes related to illness and health condition and an altered everyday life. The narratives demonstrate that the older people, especially when returning home from hospital, experience that conditions in their present lives are more or less altered. They have to relate to reduced bodily functions and pains. This force them to make adjustments in everyday life. Such adjustments may involve change of habits and activities. As this often makes them more dependent of family and friends, coping with alterations also means having to deal with changes in the relationship with significant others. As one participant said, "I could never have managed without my daughter. She has visited me every day after I returned home from hospital!” And another, "The home care is of great help, and my wife even more!”

Coping with alterations is also shown in the older people's stories related to changes in ordinary routines and surroundings. Although they find the help they receive from the home care nurses, as well as aids and technical equipment, being of great support in the situation, the same support also affect their lives in different ways. One participant told,

I have got a hospital bed as well as a wheel-chair. They (the homecare) has really facilitated my life, so says my wife. But I must admit that I wish everything was as before!

\subsection{Comprehensive Understanding}

Older people in transition from hospital to home are characterised by being exposed as human beings as well as patients. At the hospital, they are visible as disease cases, but not involved as patients with special needs. Back home their hospital stay and medical history receive little attention, and care is mainly focused on their functions and daily needs. The older people supress their needs to be informed and to share information with the health care professionals. Accordingly significant needs remain unmet in the transition process. This decreases their abilities to cope with the situation and increases their dependency on significant others. Despite concerns and insecurity the older people endure the situation and are humble during the transition process. In these circumstances they adapt to life conditions meaning that they deal with vulnerability and adjust to alterations in life.

\section{Discussion}

The aim of this study was to describe and illuminate the lived experiences of older home residents with continu- 
ing care needs during the transition from hospital to home.

Older people in transition from hospital to home have to deal with several challenges and unmet needs during the transition process. They miss being seen as individuals with a personal as well as a medical history. In accordance with previous research focusing on older people in transition, this study shows that the patients wish to be involved and participate in the discharge process [9] [10] [15] [16]. Yet, lack of information and participation in the discharge process are reported in a range of studies [3] [11] [17] [23]-[25], supporting the findings in the current study. However, although the patients missed information and the chance to being better prepared before discharge from hospital, the older persons in our study accepted their situation and were grateful for the treatment they received.

Several reports published by the Norwegian government [2] [7] [26] reflect ambitions for linking patient participation and user involvement to quality of care. These political documents are significant because they highlight care where patients are met as human beings and as patients with specific needs. The notion of being met as human beings in relation to care can also be associated with Galvin and Todres' [8] reflections on the term "humanisation". They claim that to be concerned with humanisation is to uphold a particular view or value of what it means to be human. Such a concern has to be translated into the more experiential issues of what practices can make people feel more human. The narratives in the present study indicate that the focus was on the older people's diagnosis, the medical treatment or functions and general needs, but not on them as human beings and individuals with specific needs related to their health condition. In the words of Galvin and Tordres' [8], it appears that the older people were objectified, referring to objectification as a form of dehumanisation with a potential to neglect and devalue a basic human need [8]. Hence, objectification may have made the older people vulnerable as human beings as well as patients. As human beings they felt to a large extent invisible to the professionals, while as patients they perceived that their experiences and needs in the situation failed to be taken into account. Consequently, their particular needs to share and receive information remained unmet. This may have reduced the older person's ability to manage the situation in the near and also in the more distant future, and have influenced independency, health and wellbeing negatively.

The narratives in the study reveal an absence of dialogue between the older person and the health care professionals during the transition from hospital to home. Therefore the older people lacked insight, and understanding of their medical condition. This decreased their opportunities to influence and participate during the transition process. Rather, they had to adjust to the context they at all times were part of, accepting that uniformed decisions were taken on their behalf. Self-determination means that we have the right to participate in the planning and decisions regarding the treatment and care we receive. The absence of dialogue in care and support, reflected in the participants' narratives, suggests that such rights were not taken into account. Therefore, care seemed to be more determined by routines, habits and contextual factors in the various caring systems than by the older person's lifeworld and specific needs. However, they seemed to accept this situation with few reservations. The tolerance among older patients is described in studies related to the discharge process as well as to home care. Rydeman and Törnquist [27] found that older persons reacted with resignation and accepted their hospital discharge even though they did not feel prepared. This was particularly the case when they experienced that the professionals did not listen to them or they seemed stressed and overloaded. Hvalvik and Reierson [14] found that older home residents were extremely tolerant and flexible in the helping relation, including tolerating renunciations and denigrations of own needs. Hence, the health care professionals need to be aware of how procedures, attitudes and roles facilitate or impede the patient's ability to participate in decision making concerning care options and processes. Frail older people are particularly vulnerable and exposed to practices that render the person passive in relation to their condition and treatment. Galvin and Todres [8] claim that through excessive passivity one is stripped of human dignity to varying degrees and that this can be dehumanising. Subsequently, patient participation can be considered a target as well as a means to humanise the care and to promote a healthy transition. Successful participation presupposes, as Rydeman and Törnquist [28] suggest, that the patient's resources are carefully assessed and constitute a common basis and a starting point for the professionals to involve the patient in their treatment and care. In addition, the older person's narrative need to be included, as this captures how the illness and symptoms impact her or his life [29].

To include older people's narratives means involving them as persons with their history and biography. This is vital in this context as transitions, according to Schumacher et al. [30], must be viewed within the context of the older person's life. In the transition process changes in everyday life may be experienced, and meaningful activities may be threatened. The older people in the current study tried to re-establish their lives to a kind of 
new normality in the initial time after returning home. This included adapting to changes in their health condition and incorporating professional help and new routines into daily life. Our results indicate that the alterations made them vulnerable in several ways. It is vital for health care professionals to support older people in transition by helping them to cope with changes and challenges and maintain continuity in everyday life. Therefore, they need to understand the present situation in the context and coherence of past and future. Supporting the older person to connect to the familiarity of the past as well as to move into the unfamiliarity of the future means to support a sense of continuity in their lives [8]. This is crucial for helping the older person to master and find meaning in everyday life, and to care for her or him in a healthy and humanising way.

\subsection{Conclusion}

Our findings suggest that the older people were challenged as human beings as well as patients during the transition between hospital and home. Navigating through fragmented systems of care, they had to adapt to the different traditions and procedures. Despite lack of information and participation in the process, they were thankful and humble to the systems of care they were part of. Although they underestimated the subject, their humility also encompassed rejecting own needs. To promote a healthy transition, we advocate a person-oriented approach focusing on the older person's individual needs and preferences. This means that care must be considered in the perspectives of the older person's biographical as well as medical history, and of the complexity of the situation.

\subsection{Limitations and Strengths of the Study}

The participants in this study were mainly women, and three participants had to withdraw because of worsening illness. These factors may have limited the variations in the data. Although the participants' ability to express and describe their experiences varied, extensive interviews were conducted. This resulted in descriptions that add insight into a theme that is significant to health professionals, their relations to patients and to each other within and across practice fields. These insights may contribute to improving the quality of care for older patients in transition.

\section{Acknowledgements}

The authors thank the patients for participating in the study and the leaders in the home care services in the municipalities in Telemark and Agder for their kind assistance with participant recruitment.

\section{Competing Interests}

The authors report no conflict of interest.

\section{Fund}

This work was funded by Telemark University College and University of Agder.

\section{Authors' Contributions}

The first author designed the study. Both authors collected the data and performed the structural analysis. First author drafted the manuscript, while the second author helped to interpret the findings and critically reviewed the manuscript. Both authors read and approved the final manuscript.

\section{References}

[1] Norwegian Knowledge Centre for the Health Services, Reinnleggelser av eldre i Norge [Readmission in Norwegian hospitals], 2012.

[2] Report No. 47 to the Storting (2008-2009), Samhandlingsreformen. Rett behandling —På rett sted—Til rett tid. [The Coordination Reform. Proper Treatment-At the Right Place and Right Time], Norwegian Ministry of Health and Care Services.

[3] Golden, A., Tewary, S., Dang, S. and Roos, B.A. (2010) Care Management’s Challenges and Opportunities to Reduce the Rapid Rehospitalization of Frail Community-Dwelling Older Adults. Gerontologist, 50, 451-458. http://dx.doi.org/10.1093/geront/gnq015 
[4] Coleman, E.A., Parry, C., Chalmers, S. and Min, S. (2006) The Care Transition Intervention. Archieves of Internal Medicine, 166, 1822-1828. http://dx.doi.org/10.1001/archinte.166.17.1822

[5] Naylor, M.D., Aiken, L.H., Kurtzman, E.T., Oldes, D.M. and Hirschman, K.B. (2011) The Importance of Transitional Care in Achieving Health Reform. Health Affairs, 30, 746-754. http://dx.doi.org/10.1377/hlthaff.2011.0041

[6] Meleis, A.I. and Trangenstein, P. (1994) Facilitating Transitions: Redefinition of the Nursing Mission. Nursing Outlook, 42, 255-259. http://dx.doi.org/10.1016/0029-6554(94)90045-0

[7] Report No. 10 to the Storting (2012-2013), God kvalitet-Trygge tjenester. Kvalitet og pasientsikkerhet i helse- og omsorgstjenesten. [Good Quality—Safe Services. Quality and Patient Security in the Health and Care Services], Norwegian Ministry of Health and Care Services.

[8] Galvin, K. and Todres, L. (2013) Caring and Well-Being: A Lifeworld Approach. Routeledge, London.

[9] Bauer, M., Fitzgerald, L., Haesler, E. and Manfrin, M. (2009) Hospital Discharge Planning for Frail Older People and Their Family: Are We Delivering Best Practice? A Review of the Evidence. Journal of Clinical Nursing, 8, 2539-2546. http://dx.doi.org/10.1111/j.1365-2702.2008.02685.x

[10] Dedhia, P., Kravet, S., Bulger, J., Hinson, T., Sridharan, A., Kolodner, K., Wright, S. and Howell, E. (2009) A Quality Improvement Intervention to Facilitate the Transition of Older Adults from Three Hospitals Back to Their Homes. Journal of American Geriatric Society, 57, 1540-1546. http://dx.doi.org/10.1111/j.1532-5415.2009.02430.x

[11] Dunnion, M.E. and Kelly, B. (2008) All Referrals Completed? The Issues of Liaison and Documentation When Discharging Older People from an Emergency Department to Home. Journal of Clinical Nursing, 17, 2471-2479. http://dx.doi.org/10.1111/j.1365-2702.2007.02084.x

[12] Danielsen, B. and Fjær, S. (2010) Erfaringer med å overføre syke eldre pasienter fra sykehus til kommune [Experiences Related to the Transfer of Older Patients from Hospital to Municipality]. Sykepleien Forskning, 5, 28-34. http://dx.doi.org/10.4220/sykepleienf.2010.0021

[13] Olsen, R.M. (2013) Information Exchange between Home Care and Hospital Nurses during Older Patients Transfer. PhD Thesis, Institutionen fõr Hãlsovetenskap, Mittuniversitetet, Sundsvall.

[14] Hvalvik, S. and Reierson, I.Å. (2011) Transition from Self-Supported to Supported Living: Older People’s Experiences. International Journal of Qualitative Studies on Health and Well-Being, 6, 7914. http://dx.doi.org/10.3402/qhw.v6i4.7914

[15] Foss, C. and Hofoss, D. (2011) Elderly Persons' Experiences of Participation in Hospital Discharge Process. Patient Education and Counseling, 85, 68-73. http://dx.doi.org/10.1016/j.pec.2010.08.025

[16] Foss, C., Romøren, T.I., Hofoss, D., Bragstad, L. and Kirkevold, M. (2012) Eldres erfaringer med utskriving frasykehus [Elderly Persons’ Experiences with Hospital Discharge]. Sykepleien Forskning, 7, 324-33. http://dx.doi.org/10.4220/sykepleienf.2012.0154

[17] Bragstad, L.K., Kirkevold, M., Hofoss, D. and Foss, C. (2012) Factors Predicting a Successful Post-Discharge Outcome for Individuals Aged 80 Years and Over. International Journal of Integrated Care, 12, 1-10.

[18] Dahlberg, K., Dahlberg, H. and Nystrøm, M. (2008) Reflective Life World Research. Student literature, Lund.

[19] Gadamer, H.G. (1989) Truth and Method. 2nd Edition, Sheed and Ward, London.

[20] Ricoeur, P. (1976) Interpretation Theory: Discourse and the Surplus of Meaning. Texas Christian University Press, Fort Worth.

[21] World Medical Association (2008) Declaration of Helsinki, Ethical Principles for Medical Research Involving Human Subjects.

[22] Beauchamp, T.L. and Childress, J.F. (2009) Principles of Biomedical Ethics. 6th Edition, University Press Inc, Oxford.

[23] Hvalvik, S. and Reierson, I.Å. (2015) Striving to Maintain a Dignified Life for the Patient in Transition: Next of Kin’s Experiences during the Transition Process of an Older Person in Transition from Hospital to Home. International Journal of Qualitative Studies on Health and Well-Being, 10, 1-10. http://dx.doi.org/10.3402/qhw.v10.26554

[24] Bragstad, L.K., Kirkevold, M., Hofoss, D. and Foss, C. (2014) Informal Caregivers’ Participation When Older Adults in Norway Are Discharged from the Hospital. Health \& Social Care in the Community, 22, 155-168. http://dx.doi.org/10.1111/hsc.12071

[25] Naylor, M.D. (2002) Transitional Care of Older Adults. Annual Review of Clinical Nursing, 20, 127-147.

[26] Report Nr. 29 to the Storting (2012-2013) Morgendagens Omsorg [Tomorrow’s Care]. Norwegian Ministry of Health and Care Services.

[27] Rydeman, I.B. and Törnquist, L. (2010) Getting Prepared for Life at Home in the Discharge Process: Form the Perspective of the Older Persons and Their Relatives. International Journal of Older People Nursing, 5, 254-264. http://dx.doi.org/10.1111/j.1748-3743.2009.00190.x 
[28] Rydeman, I.B. and Törnquist, L. (2006) The Patient’s Vulnerability, Dependence and Exposed Situation in the Discharge Process: Experiences of District Nurses, Geriatric Nurses and Social Workers. Journal of Clinical Nursing, 15, 1299-1307. http://dx.doi.org/10.1111/j.1365-2702.2006.01379.x

[29] Ekman, I., Swedberg, K., Taft, C., Lindseth, A., Norberg, A., Brink, E., Carlsson, J., Dahlin-Ivanoff, S., Johansson, I.L., Kjellgren, K., Lidén, E., Öhlen, J., Olsson, L.E., Rosén, H., Rydmark, M. and Sunnerhagen, K.S. (2011) Person-Centered Care: Ready for Prime Time. European Journal of Cardiovascular Nursing, 10, 248-251. http://dx.doi.org/10.1016/j.ejcnurse.2011.06.008

[30] Schumacher, K.L., Jones, P.S. and Meleis, A.I. (1999) Helping Elderly Persons in Transition: A Framework for Research and Practice. In: Swanson, E.A. and Tripp-Reimer, T., Eds., Life Transitions in the Older Adult: Issues for Nurses and Other Health Professionals, Springer, New York, 1-26. 